\title{
Association of Human Leukocyte Antigen Class I Polymorphism with Spontaneous Clearance of Hepatitis B Surface Antigen in Qidong Han Population
}

\author{
Fengqin Miao, ${ }^{1,2}$ Hang Sun, ${ }^{2}$ Ning Pan, ${ }^{1,2}$ Jinhuan Xu, ${ }^{2}$ Jie Qiu, ${ }^{2,3}$ Yuqing Shen, \\ Wei Xie, ${ }^{2}$ and Jianqiong Zhang ${ }^{1,2}$ \\ ${ }^{1}$ Medical School, Ministry of Education, Southeast University, Nanjing, Jiangsu 210009, China \\ ${ }^{2}$ Key Laboratory of Developmental Genes and Human Disease, Ministry of Education, Southeast University, Nanjing, \\ Jiangsu 210096, China \\ ${ }^{3}$ The Second Affiliated Hospital of Southeast University, Nanjing, Jiangsu 210008, China
}

Correspondence should be addressed to Jianqiong Zhang; zhjq@seu.edu.cn

Received 29 May 2013; Revised 27 September 2013; Accepted 29 September 2013

Academic Editor: Basak Kayhan

Copyright (C) 2013 Fengqin Miao et al. This is an open access article distributed under the Creative Commons Attribution License, which permits unrestricted use, distribution, and reproduction in any medium, provided the original work is properly cited.

\begin{abstract}
Aim. To investigate whether HLA class I polymorphisms could influence the clearance of hepatitis B surface antigen (HBsAg) in Qidong Han population. Methods. We genotyped HLA-A, -B, and -C loci of 448 individuals with HBV persistent infection and 140 persons with spontaneous clearance of HBsAg by polymerase chain reaction with sequencing based typing (PCR/SBT). All the individuals were unrelated males enrolled from Qidong Han population and were followed up for 10 years. Results. The frequency of $H L A-A^{*} 33: 03: 01 G$ was increased in persistent HBV infection group ( $P$ value is 0.028), while frequency of $H L A$ $B^{*}$ 13:01:01G was increased in HBsAg clearance group ( $P$ value is 0.0004$)$. Conclusion. These findings suggested that the host HLA class I polymorphism is an important factor in determining the outcomes of HBV infection.
\end{abstract}

\section{Introduction}

Hepatitis B virus (HBV) infection is a major public health problem. Two billion people are expected to be infected with HBV during their lifetime and about 350 million are estimated to be chronic carriers $[1,2]$. Nowadays, there are about 120 million HBV chronic carriers in China [3]. HBV infection can cause broad-spectrum diseases, including chronic hepatitis, liver cirrhosis, and hepatocellular carcinoma [4]. The mechanism of HBV clearance and pathogenesis is not yet clearly defined, but host genetic component is one of the critical contributors, which includes age, sex, immune response, and so forth [5-8]. Therefore, understanding the role of host genetic variability in the pathogenesis of HBV infection will help us to uncover the basis for this viral persistence.

Human leukocyte antigen (HLA) is an integral component of the immune response on which majority of host genetic studies have focused. Numerous reports described the associations of highly polymorphic HLA gene with the outcome of a wide range of infectious diseases. It is because antiviral cytotoxic T lymphocytes (CTLs) are believed to play a major role in eradication of infection by virtue of their capacity to identify and kill virus-infected cells through recognition of viral peptides presented by HLA class I molecules [9]. Thus, HLA molecules are considered to govern the pathology of disease, progression, or regression along with the viral and environmental factors.

The genes of the HLA locus are located on the short arm of chromosome 6. They are arranged in three clusters: class I, class II, and class III. Many previous studies have shown the associations of certain HLA class I genes with the course of HBV infection, but these associations are inconsistent even within the same population $[10,11]$. Han is the largest ethnic group in China. Among Han resident areas, Qidong 
is a famous place in China where the habitants have high incidence of $\mathrm{HBV}$ infection. In this study, to determine whether the HLA I alleles are associated with resistance or susceptibility to HBV infection in Qidong Han people, we analyzed the polymorphism of HLA I alleles in individuals who had HBV persistent infection or those who had HBsAg clearance using high resolution sequencing technique.

\section{Materials and Methods}

2.1. Ethics Statement. The protocol was approved by the Ethics Committee of the Qidong Liver Cancer Institute, and all patients provided written, informed consent before enrollment.

2.2. Study Subjects. A total of 728 unrelated male individuals with hepatitis B surface antigen (HBsAg) positive in sera were enrolled in the Institute of Liver Cancer of Qidong in 1995. They were followed up for 10 years and tested for $\mathrm{HBV}$ infection again. In 2005, 588 individuals were included in this cohort because of loss to follow-up and exclusion of the patients who were treated with anti-HBV therapy. Among these 588 persons, 448 remained HBsAg positive (named HBV persistent infection group), while 140 were negative for HBsAg but positive for both anti-hepatitis $\mathrm{B}$ virus core antigen $(\mathrm{HBc}$ ) and anti-HBsAg (named $\mathrm{HBsAg}$ clearance group). None of the subjects were positive for hepatitis $\mathrm{C}$ virus (HCV), hepatitis D virus (HDV), and human immunodeficiency virus (HIV) antibody. All of them are Han population.

2.3. Serologic and Virologic Tests. Plasma samples were obtained from all the subjects and stored at $-20^{\circ} \mathrm{C}$. Their serologic status with regard to $\mathrm{HBsAg}$, anti- $\mathrm{HBs}$, anti-HBc, hepatitis B virus e antigen ( $\mathrm{HBeAg}$ ), and anti-HBe was determined by enzyme-linked immunosorbent assay according to the manufacturer's instructions (Boehringer-Mannheim, Munich, Germany).

2.4. Extraction of Genomic DNA and HLA Allele Genotyping. Genomic DNA for each individual was extracted from peripheral blood mononuclear cells using the QIAamp DNA blood kit (Qiagen Inc., Chatsworth, CA). All DNA samples $(100-200 \mathrm{ng} / \mathrm{mL})$ were stored at $4^{\circ} \mathrm{C}$ (short term) or $-20^{\circ} \mathrm{C}$ (long term) in TE buffer (10 mM Tris- $\mathrm{HCl}, \mathrm{pH} 8.0,2 \mathrm{mM}$ ethylene diamine tetraacetic acid) and diluted to $10-12 \mathrm{ng} / \mathrm{mL}$ in PCR.

Genomic DNA was amplified by the standard HLA locusspecific primers [12]. According to the routine sequencebased typing (SBT) method, exons 2 and 3 were sequenced in forward and reverse directions using a 3730XL DNA analyzer (Applied Biosystems, Foster City, CA) and BigDye Terminator v3.1 Cycle Sequencing Ready Reaction Kit (Applied Biosystems). The sequences were then analyzed using the online software SBT Interface (MHC database; National Center for Biotechnology Information; http://www. ncbi.nlm.nih.gov/mhc/). All groups of HLA alleles that have identical nucleotide sequences across the exons encoding the peptide binding domains (exons 2 and 3 for HLA class I alleles) are designated by a code, such as $A^{*} 33: 03: 01 G$, which essentially contains $A^{*} 33: 03: 01, A^{*} 33: 15, A^{*} 33: 25$, and so on (http://hla.alleles.org/alleles/g_groups.html).

2.5. Statistical Analysis. The allele frequency was calculated as the number of the allele divided by the double numbers of the total samples. The significance of allelic associations was determined either by chi-square test or by Fisher's exact test (when there were less than five subjects in a cell). In order to reduce the number of comparisons with inadequate power, only alleles with frequency not less than 3\% (29 alleles in this population) were analyzed. The level of significance was adjusted for multiple testing using the Bonferroni correction. According to the Bonferroni correction, the frequency of HLA allele was considered to be statistically different only when uncorrected $P$ value was less than Pc $(0.05 / 29=0.0017)$. HLA genotypes with frequency not less than $3 \%$ were checked for the Hardy-Weinberg equilibrium using $\chi^{2}$ test. Data were analyzed by SPSS 13.0 data analysis software package. Odds ratios (OR) and their 95\% confidence intervals were calculated.

\section{Results}

3.1. Patient Characteristics. 588 Qidong Han persons who were tested as HBsAg positive in 1995 were included in this study. 448 were classified as $\mathrm{HBV}$ persistent infection group as they remained $\mathrm{HBs} \mathrm{Ag}$ positive 10 years of later. The $\mathrm{HBsAg}$ clearance group includes the remaining 140 individuals who were negative for $\mathrm{HBsAg}$ but positive for both anti-HBc and anti-HBs after 10 years follow-up. Age distribution showed no statistical difference between the two groups.

3.2. Frequencies of $H L A-A, H L A-B$, and HLA-C Alleles in the Study Groups. A total of 31 HLA-A alleles, 54 HLA-B alleles, and 35 HLA-C alleles were detected in the two study groups (Tables 1-3). Among them, the frequencies of 29 alleles were higher than $3 \%$. $A^{*} 24: 02: 01 G$ was the most frequent HLA-A allele (Table 1), while $B^{*} 46: 01: 01 G$ and $B^{*} 40: 01: 01 G$ were the most frequent HLA-B alleles (Table 2), and $C^{*}$ 01:02:01G was the most frequent HLA-C allele (Table 3). Meanwhile, four new alleles (HLA-C ${ }^{*}$ 12:10:02, $H L A-B^{*}$ 40:122, $H L A-B^{*}$ 40:127, and $\left.H L A-B^{*} 55: 49\right)$ were identified by our previous study from this cohort and named by the WHO Nomenclature Committee $[13,14]$. HLA genotype frequencies were consistent with Hardy-Weinberg equilibrium $(P>0.05)$.

\subsection{Comparison of Frequency of HLA-A, HLA-B, and HLA-C} Alleles between the Persistent Infection and HBsAg Clearance Groups. To maintain statistical power, only those alleles with the frequencies not less than 3\% were compared between the persistent infection and $\mathrm{HBsAg}$ clearance groups. The frequency of $H L A-A^{*}$ 33:03:01G allele in the HBV persistent infection group was higher than that in the HBsAg clearance group $(6.36 \%$ versus $2.86 \%, P=0.025, O R=2.31,95 \%$ CI: 1.09-4.90), whereas the frequency of $H L A-B^{*} 13: 01: 01 G$ was higher in the HBsAg clearance group than that in the 
TABLE 1: Frequencies of HLA-A alleles in each study group.

\begin{tabular}{|c|c|c|c|c|}
\hline \multirow{2}{*}{ HLA-A alleles } & \multicolumn{2}{|c|}{ Persistent infection group $(2 n=896)$} & \multicolumn{2}{|c|}{ HBsAg clearance group $(2 n=280)$} \\
\hline & Allele frequency (\%) & Count & Allele frequency (\%) & Count \\
\hline$A^{*} 01: 17$ & 0.11 & 1 & 0.00 & 0 \\
\hline$A^{*} 01: 01: 01 G$ & 2.00 & 18 & 2.86 & 8 \\
\hline$A^{*} 02: 01: 25$ & 0.00 & 0 & 0.36 & 1 \\
\hline$A^{*} 02: 03: 01 G$ & 1.34 & 12 & 1.43 & 4 \\
\hline$A^{*} 02: 06: 01 G$ & 6.58 & 59 & 5.71 & 16 \\
\hline$A^{*} 02: 07: 01 G$ & 9.93 & 89 & 9.64 & 27 \\
\hline$A^{*} 02: 10$ & 0.33 & 3 & 0.00 & 0 \\
\hline$A^{*} 02: 11: 01 G$ & 0.22 & 2 & 0.36 & 1 \\
\hline$A^{*} 02: 53 N$ & 0.11 & 1 & 0.00 & 0 \\
\hline$A^{*} 02: 01: 01 G$ & 15.29 & 137 & 16.79 & 47 \\
\hline$A^{*} 03: 01: 01 G$ & 0.33 & 3 & 0.71 & 2 \\
\hline$A^{*} 11: 01: 01 G$ & 18.30 & 164 & 21.07 & 59 \\
\hline$A^{*} 11: 02: 01 G$ & 4.35 & 39 & 5.71 & 16 \\
\hline$A^{*} 23: 01: 01 G$ & 0.00 & 0 & 0.36 & 1 \\
\hline$A^{*} 24: 04$ & 0.11 & 1 & 0.36 & 1 \\
\hline$A^{*} 24: 07$ & 0.33 & 3 & 0.00 & 0 \\
\hline$A^{*} 24: 08$ & 0.11 & 1 & 0.00 & 0 \\
\hline$A^{*} 24: 10$ & 0.11 & 1 & 0.00 & 0 \\
\hline$A^{*} 24: 20$ & 0.33 & 3 & 0.71 & 2 \\
\hline$A^{*} 24: 77$ & 0.00 & 0 & 0.36 & 1 \\
\hline$A^{*} 24: 02: 01 G$ & 22.32 & 200 & 20.36 & 57 \\
\hline$A^{*} 26: 01: 01 G$ & 2.57 & 23 & 2.14 & 6 \\
\hline$A^{*} 29: 01: 01 G$ & 0.22 & 2 & 0.00 & 0 \\
\hline$A^{*} 30: 01: 01 G$ & 2.23 & 20 & 1.43 & 4 \\
\hline$A^{*} 31: 01: 02 G$ & 5.25 & 47 & 5.00 & 14 \\
\hline$A^{*} 32: 01: 01 G$ & 0.22 & 2 & 0.36 & 1 \\
\hline$A^{*} 33: 11$ & 0.11 & 1 & 0.71 & 2 \\
\hline$A^{*} 33: 03: 01 G^{*}$ & 6.36 & 57 & 2.86 & 8 \\
\hline$A^{*} 34: 01: 01$ & 0.11 & 1 & 0.00 & 0 \\
\hline$A^{*} 68: 01: 02 G$ & 0.45 & 4 & 0.00 & 0 \\
\hline$A^{*} 69: 01$ & 0.22 & 2 & 0.71 & 2 \\
\hline
\end{tabular}

${ }^{*} P=0.025$ ( $\mathrm{Pc}=0.0017$, so $A^{*}$ 33:03:01G does not reach statistically significant after Bonferroni correction).

persistent group $(8.57 \%$ versus $3.46 \%, P=0.0004, O R=2.62$, 95\% CI: 1.51-4.54). However, only the frequency of HLA$B^{*} 13: 01: 01 G$ increased significantly in HBsAg clearance group after the Bonferroni correction.

\section{Discussion}

It is doubtless that host genetic factors are associated with the clinical outcome of different infectious diseases. The moststudied host factors that might affect the susceptibility to viral infection are HLA genes $[15,16]$. Among HLA genes, HLA class I genes encode HLA-A, HLA-B, and HLA-C proteins which are expressed on the surface of all nucleated cells. HLA class I molecule can bind viral peptides and present them on the surface of virus-infected cells, which can be recognized by CD8+CTL. While HLA class II molecule can bind and present viral peptides as well, the cells can be recognized by CD4+ T lymphocytes. Both HLA class I and HLA class II are found to be associated with the outcomes of HBV infection $[11,17,18]$. Some HLA class I molecules can function as ligands of natural killer (NK) cell receptors and become important regulators for NK cell $[19,20]$ and CD8+ T cell $[21,22]$. Association studies on the outcomes of other viral infections, such as HCV [23], HIV [24, 25], human papillomavirus [26], and Cytomegalovirus (CMV) [27], supported the important role of HLA I when it functioned as ligands for Killer cell immunoglobulin-like receptor (KIR). Gao et al. observed that some combinations of KIR and specific HLA-C gene were correlated with the occurrence of hepatitis B [28]. We also reported that the polymorphisms of HLA class I and KIR could influence the development 
TABLE 2: Frequencies of HLA-B alleles in each study group.

\begin{tabular}{|c|c|c|c|c|}
\hline \multirow{2}{*}{ HLA-B alleles } & \multicolumn{2}{|c|}{ Persistent infection group $(2 n=896)$} & \multicolumn{2}{|c|}{ HBsAg clearance group $(2 n=280)$} \\
\hline & Allele frequency (\%) & Count & Allele frequency (\%) & Count \\
\hline$B^{*} 07: 02: 01 G$ & 0.11 & 1 & 0.00 & 0 \\
\hline$B^{*} 08: 01: 01 G$ & 0.22 & 2 & 0.00 & 0 \\
\hline$B^{*} 08: 18$ & 0.11 & 1 & 0.00 & 0 \\
\hline$B^{*} 13: 01: 01 G^{*}$ & 3.46 & 31 & 8.57 & 24 \\
\hline$B^{*} 13: 02: 01 G$ & 3.46 & 31 & 2.86 & 8 \\
\hline$B^{*} 13: 06$ & 0.11 & 1 & 0.00 & 0 \\
\hline$B^{*} 15: 02: 01 G$ & 2.90 & 26 & 2.5 & 7 \\
\hline$B^{*} 15: 03: 01 G$ & 0.11 & 1 & 0.00 & 0 \\
\hline$B^{*} 15: 07: 01 G$ & 0.22 & 2 & 0.36 & 1 \\
\hline$B^{*} 15: 11: 01 G$ & 3.24 & 29 & 4.26 & 12 \\
\hline$B^{*} 15: 12: 01 G$ & 0.47 & 4 & 0.00 & 0 \\
\hline$B^{*} 15: 15$ & 0.00 & 0 & 0.36 & 1 \\
\hline$B^{*} 15: 18: 01 G$ & 1.34 & 12 & 1.43 & 4 \\
\hline$B^{*} 15: 25: 01 G$ & 0.22 & 2 & 0.71 & 2 \\
\hline$B^{*} 15: 27: 01$ & 2.01 & 18 & 2.14 & 6 \\
\hline$B^{*} 15: 58$ & 0.45 & 4 & 0.00 & 0 \\
\hline$B^{*} 15: 01: 01 G$ & 12.05 & 108 & 10 & 28 \\
\hline$B^{*} 18: 02$ & 0.11 & 1 & 0.00 & 0 \\
\hline$B^{*} 18: 01: 01 G$ & 0.22 & 2 & 0.00 & 0 \\
\hline$B^{*} 27: 04: 01 G$ & 4.35 & 39 & 4.29 & 12 \\
\hline$B^{*} 27: 05: 02 G$ & 0.59 & 5 & 0.71 & 2 \\
\hline$B^{*} 27: 06$ & 0.11 & 1 & 0.00 & 0 \\
\hline$B^{*} 35: 10$ & 0.11 & 1 & 0.00 & 0 \\
\hline$B^{*} 35: 72$ & 0.11 & 1 & 0.00 & 0 \\
\hline$B^{*} 35: 01: 01 G$ & 0.59 & 5 & 0.71 & 2 \\
\hline$B^{*} 37: 01: 01 G$ & 0.33 & 3 & 1.79 & 5 \\
\hline$B^{*} 38: 02: 01 G$ & 0.45 & 4 & 0.00 & 0 \\
\hline$B^{*} 39: 01: 01 G$ & 0.33 & 3 & 1.07 & 3 \\
\hline$B^{*} 40: 02: 01 G$ & 3.57 & 32 & 3.57 & 10 \\
\hline$B^{*} 40: 03$ & 0.33 & 3 & 0.00 & 0 \\
\hline$B^{*} 40: 06: 01 G$ & 3.01 & 27 & 3.57 & 10 \\
\hline$B^{*} 40: 11: 01$ & 0.33 & 3 & 0.00 & 0 \\
\hline$B^{*} 40: 20$ & 0.11 & 1 & 0.00 & 0 \\
\hline$B^{*} 40: 21$ & 0.11 & 1 & 0.00 & 0 \\
\hline$B^{*} 40: 40$ & 1.11 & 10 & 0.00 & 0 \\
\hline$B^{*} 40: 01: 01 G$ & 16.52 & 148 & 15.36 & 43 \\
\hline$B^{*} 41: 01$ & 0.00 & 0 & 0.36 & 1 \\
\hline$B^{*} 44: 03: 01 G$ & 0.33 & 3 & 0.00 & 0 \\
\hline$B^{*} 44: 03: 02$ & 0.11 & 1 & 0.00 & 0 \\
\hline$B^{*} 46: 01: 01 G$ & 18.30 & 164 & 16.43 & 46 \\
\hline$B^{*} 48: 01: 01 G$ & 0.33 & 3 & 0.71 & 2 \\
\hline$B^{*} 51: 02: 01$ & 0.33 & 3 & 0.00 & 0 \\
\hline$B^{*} 51: 01: 01 G$ & 1.00 & 9 & 0.36 & 1 \\
\hline$B^{*} 52: 01: 01 G$ & 0.11 & 1 & 1.07 & 3 \\
\hline$B^{*} 52: 08$ & 0.11 & 1 & 0.00 & 0 \\
\hline$B^{*} 54: 01: 01 G$ & 6.03 & 54 & 7.14 & 20 \\
\hline
\end{tabular}


TABle 2: Continued.

\begin{tabular}{|c|c|c|c|c|}
\hline \multirow{2}{*}{ HLA-B alleles } & \multicolumn{2}{|c|}{ Persistent infection group $(2 n=896)$} & \multicolumn{2}{|c|}{ HBsAg clearance group $(2 n=280)$} \\
\hline & Allele frequency (\%) & Count & Allele frequency (\%) & Count \\
\hline$B^{*} 55: 02: 01 G$ & 5.58 & 50 & 4.64 & 13 \\
\hline$B^{*} 55: 12$ & 0.22 & 2 & 0.36 & 1 \\
\hline$B^{*} 56: 01: 01 G$ & 0.78 & 7 & 0.36 & 1 \\
\hline$B^{*} 56: 03$ & 0.22 & 2 & 0.00 & 0 \\
\hline$B^{*} 57: 01: 01 G$ & 2.23 & 20 & 2.86 & 8 \\
\hline$B^{*} 58: 01: 01 G$ & 0.59 & 5 & 0.36 & 1 \\
\hline$B^{*} 59: 01: 01 G$ & 0.70 & 6 & 1.07 & 3 \\
\hline$B^{*} 67: 01: 01$ & 0.22 & 2 & 0.00 & 0 \\
\hline
\end{tabular}

${ }^{*} P=0.0004$ ( $P<$ Pc. It is statistically significant after the Bonferroni correction).

TABLE 3: Frequencies of HLA-C alleles in each study group.

\begin{tabular}{|c|c|c|c|c|}
\hline \multirow{2}{*}{ HLA-C alleles } & \multicolumn{2}{|c|}{ Persistent infection group $(2 n=896)$} & \multicolumn{2}{|c|}{ HBsAg clearance group $(2 n=280)$} \\
\hline & Allele frequency $(\%)$ & Count & Allele frequency (\%) & Count \\
\hline$C^{*} 01: 02: 01 G$ & 26.00 & 233 & 26.07 & 73 \\
\hline$C^{*} 01: 02: 03$ & 0.11 & 1 & 0.36 & 1 \\
\hline$C^{*} 01: 03: 01 G$ & 1.00 & 9 & 1.07 & 3 \\
\hline$C^{*} 03: 02: 01 G$ & 4.58 & 41 & 3.21 & 9 \\
\hline$C^{*} 03: 04: 01 G$ & 11.83 & 106 & 14.29 & 40 \\
\hline$C^{*} 03: 04: 04$ & 0.00 & 0 & 0.71 & 2 \\
\hline$C^{*} 03: 32$ & 0.33 & 3 & 0.00 & 0 \\
\hline$C^{*} 03: 69$ & 0.11 & 1 & 0.00 & 0 \\
\hline$C^{*} 03: 03: 01 G$ & 8.26 & 74 & 9.29 & 26 \\
\hline$C^{*} 04: 03$ & 0.22 & 2 & 0.36 & 1 \\
\hline$C^{*} 04: 01: 01 G$ & 6.92 & 62 & 3.93 & 11 \\
\hline$C^{*} 06: 02: 01 G$ & 4.47 & 40 & 4.29 & 12 \\
\hline$C^{*} 06: 06$ & 0.11 & 1 & 0.00 & 0 \\
\hline$C^{*} 07: 02: 04$ & 0.11 & 1 & 0.00 & 0 \\
\hline$C^{*} 07: 04: 01 G$ & 0.89 & 8 & 1.07 & 3 \\
\hline$C^{*} 07: 08$ & 0.22 & 2 & 0.00 & 0 \\
\hline$C^{*} 07: 27: 01$ & 0.22 & 2 & 0.00 & 0 \\
\hline$C^{*} 07: 43$ & 0.33 & 3 & 0.00 & 0 \\
\hline$C^{*} 07: 51$ & 0.11 & 1 & 0.00 & 0 \\
\hline$C^{*} 07: 56: 01$ & 0.11 & 1 & 0.36 & 1 \\
\hline$C^{*} 07: 01: 01 G$ & 0.11 & 1 & 0.00 & 0 \\
\hline$C^{*} 07: 02: 01 G$ & 12.72 & 114 & 13.93 & 39 \\
\hline$C^{*} 08: 03: 01$ & 0.22 & 2 & 0.36 & 1 \\
\hline$C^{*} 08: 01: 01 G$ & 6.47 & 58 & 7.86 & 22 \\
\hline$C^{*} 12: 02: 01 G$ & 4.91 & 44 & 5.00 & 14 \\
\hline$C^{*} 12: 03: 01 G$ & 0.56 & 5 & 0.00 & 0 \\
\hline$C^{*} 14: 02: 01 G$ & 7.14 & 64 & 4.29 & 12 \\
\hline$C^{*} 14: 03$ & 0.11 & 1 & 0.00 & 0 \\
\hline$C^{*} 15: 02: 01 G$ & 1.34 & 12 & 2.14 & 6 \\
\hline$C^{*} 15: 08$ & 0.11 & 1 & 0.00 & 0 \\
\hline$C^{*} 15: 15$ & 0.00 & 0 & 0.36 & 1 \\
\hline$C^{*} 15: 17$ & 0.22 & 2 & 0.00 & 0 \\
\hline$C^{*} 16: 02: 01 G$ & 0.11 & 1 & 0.71 & 2 \\
\hline$C^{*} 17: 01: 01 G$ & 0.00 & 0 & 0.36 & 1 \\
\hline
\end{tabular}


of HBV-associated liver cancer [29]. To investigate whether HLA I molecules as KIR ligands could influence the HBsAg clearance in this cohort, we grouped the HLA-A, HLA-B, and HLA-C alleles into three KIR ligand categories: Bw4, HLAC group 1, and HLA-C group 2 as described [30], and then compared their frequencies between the persistent infection and HBsAg clearance groups. However, no association was observed (data not shown).

The relationship between HLA class I polymorphisms and the outcome of HBV infection has been explored previously, but this relationship does not appear to be universal since the investigated populations are different. In Taiwanese Aborigines, $H L A-A^{*} 0206$ was susceptible to $\mathrm{HBV}$ infection and chronicity, and $H L A-B^{*} 4001$ was likely to be associated with the elimination of the virus [10]. In American Caucasians, $H L A-A^{*} 01-B^{*} 08-D R B 1^{*} 03, B^{*} 44-C w 1601$, and $B^{*} 44-$ $C w^{*} 0501$ haplotypes were associated with viral persistence, and $H L A-A^{*} 0301$ was associated with viral clearance. In European Caucasians, $H L A-B^{*} 8$ was associated with nonresponse to HBV vaccination [11]. Karan et al., in their studies in Turkey, have reported that HLA-A24 and CW1 were protective against chronic HBV [31]. Besides that, in eastern Turkey, HLA-B35 and HLA-CW4 were significantly higher in the chronic HBV group than those in the spontaneously recovered group [32].

In this study, we investigated a cohort of Qidong Han population who lived in an area of high prevalence of HBV infection. The samples were made of unrelated males and were followed up for 10 years. No previous prospective cohort study has been conducted to clarify the relationship between the polymorphisms of HLA alleles and the outcome of HBV infection in such a population. We found that HLA$A^{*} 33: 03: 01 G$ was more frequent in the HBV persistent infection group than in the HBsAg clearance group (6.36\% versus $2.86 \%, P=0.025$, OR $=2.31,95 \%$ CI: 1.09-4.90), which was consistent with the results found in northern Iran [33] and in Korean population [34] although in these populations, the difference did not reach statistically significant level after correction.

The frequency of $H L A-B^{*} 13: 01: 01 G$ was significantly higher in the HBsAg clearance group than that in the persistent group $(8.57 \%$ versus $3.46 \%, P=0.0004, O R=2.62$, $95 \%$ CI: 1.51-4.54), which revealed that $H L A-B^{*} 13: 01: 01 G$ was associated with a protective effect against persistent $\mathrm{HBV}$ infection in this Qidong Han population. $H L A-B^{*}$ 13:01:01G is not a KIR ligand because it does not carry a $B w 4$ motif. Therefore, it is unlikely that NK cell can function through this KIR-HLA interaction. Interestingly, the frequencies of $H L A$ $B^{*} 13: 02: 01 G$ were almost identical in the two groups $(2.86 \%$ in HBsAg clearance group versus $3.46 \%$ in persistent infection group). $H L A-B^{*}$ 13:02:01G differs from $H L A-B^{*}$ 13:01:01G for only three amino acids at positions 94,95 , and 97 . This threeamino-acid difference probably affects the conformation of the MHC binding grooves and results in their abilities to present viral peptide to CD8+ CTLs, which leads to different prognosis after HBV infection. This possible molecular mechanism needs to be tested in the future study.

In summary, we found that $H L A-B^{*}$ 13:01:01G was associated with a protective effect against persistent $\mathrm{HBV}$ infection in Qidong Han population. Our study provides a new clue about the influence of HLA class I diversity on the natural history of HBV infection in this population. These findings suggest that the host HLA polymorphism is an important factor in determining the outcome of HBV infection. Studies of the underlying molecular mechanisms need to be carried out in the future.

\section{Conflict of Interests}

The authors have declared that there is no conflict of interests.

\section{Acknowledgments}

The authors thank the Qidong Liver Cancer Institute for providing the samples. They would like to thank Dr. Youji $\mathrm{He}$ for critical reading of the paper. This work is funded by the National Natural Science Foundation (30571703), National Natural Science Foundation for Young Scholars (81201601), National Science Foundation for Distinguished Young Scholars (30325017) of China, Science Foundation of Department of Health of Jiangsu Province H200745), and Science Foundation of Science and Technology Bureau of Nanjing (200702067). The funders had no role in study design, data collection and analysis, decision to publish, or preparation of the paper.

\section{References}

[1] D. Lavanchy, "Hepatitis B virus epidemiology, disease burden, treatment, arid current and emerging prevention and control measures," Journal of Viral Hepatitis, vol. 11, no. 2, pp. 97-107, 2004.

[2] World Health Organization and B. Hepatitis, "World Health Organization Fact Sheet No. 204,” WHO Web site, 2008.

[3] X. C. Guo and Y. Q. Wu, "A review: progress of prevention and control on viral hepatitis in China," Biomedical and Environmental Sciences, vol. 12, no. 3, pp. 227-232, 1999.

[4] D. Ganem and A. M. Prince, "Hepatitis B virus infectionnatural history and clinical consequences," The New England Journal of Medicine, vol. 350, no. 11, pp. 1118-1129, 2004.

[5] C.-J. Chu and A. S. F. Lok, "Clinical significance of hepatitis B virus genotypes," Hepatology, vol. 35, no. 5, pp. 1274-1276, 2002.

[6] F.-S. Wang, "Current status and prospects of studies on human genetic alleles associated with hepatitis B virus infection," World Journal of Gastroenterology, vol. 9, no. 4, pp. 641-644, 2003.

[7] M. Thursz, "Genetic susceptibility in chronic viral hepatitis," Antiviral Research, vol. 52, no. 2, pp. 113-116, 2001.

[8] A. J. Frodsham and A. V. S. Hill, "Genetics of infectious diseases," Human Molecular Genetics, vol. 13, no. 2, pp. R187R194, 2004.

[9] F. V. Chisari and C. Ferrari, "Hepatitis B virus immunopathology," Springer Seminars in Immunopathology, vol. 17, no. 2-3, pp. 261-281, 1995.

[10] Y. F. Wu, L. Y. Wang, T. D. Lee et al., "HLA phenotypes and outcomes of hepatitis B virus infection in Taiwan," Journal of Medical Virology, vol. 72, no. 1, pp. 17-25, 2004.

[11] C. L. Thio, D. L. Thomas, P. Karacki et al., "Comprehensive analysis of class I and class II HLA antigens and chronic 
hepatitis B virus infection," Journal of Virology, vol. 77, no. 22, pp. 12083-12087, 2003.

[12] P. P. J. Dunn, S. T. Cox, and A.-M. Little, "Sequencing protocols for detection of HLA class I polymorphism," Methods in Molecular Biology, vol. 210, pp. 191-222, 2003.

[13] H. Sun, F. Miao, N. Pan, Y. Shen, W. Xie, and J. Zhang, "Identification of a novel HLA-C allele, C ${ }^{*} 12: 10: 02$, in a Chinese individual," Tissue Antigens, vol. 76, no. 5, pp. 424-425, 2010.

[14] F. Miao, H. Sun, N. Pan, Y. Shen, W. Xie, and J. Zhang, "Two novel HLA class I alleles, HLA-B* 40:122 and HLA-B* 40:127," Tissue Antigens, vol. 77, no. 2, pp. 156-157, 2011.

[15] A. McMichael and P. Klenerman, "HIV/AIDS: HLA leaves its footprints on HIV," Science, vol. 296, no. 5572, pp. 1410-1411, 2002.

[16] A. T. Tan, S. Koh, V. Goh, and A. Bertoletti, "Understanding the immunopathogenesis of chronic hepatitis B virus: an Asian prospective," Journal of Gastroenterology and Hepatology, vol. 23, no. 6, pp. 833-843, 2008.

[17] Y. Y. Xu, J. Y. Yu, Y. W. Zhong et al., "Association between the frequency of class II HLA antigens and the susceptibility to intrauterine infection of hepatitis B virus," International Journal of Biological Sciences, vol. 4, no. 2, pp. 111-115, 2008.

[18] G. Yang, J. Liu, S. Han et al., "Association between hepatitis $B$ virus infection and HLA-DRB1 genotyping in Shaanxi Han patients in northwestern China," Tissue Antigens, vol. 69, no. 2, pp. 170-175, 2007.

[19] L. Moretta and A. Moretta, "Unravelling natural killer cell function: triggering and inhibitory human NK receptors," EMBO Journal, vol. 23, no. 2, pp. 255-259, 2004.

[20] R. Castriconi, C. Cantoni, M. D. Chiesa et al., "Transforming growth factor $\beta 1$ inhibits expression of NKP30 and NKG2d receptors: consequences for the NK-mediated killing of dendritic cells," Proceedings of the National Academy of Sciences of the United States of America, vol. 100, no. 7, pp. 4120-4125, 2003.

[21] V. M. Braud, H. Aldemir, B. Breart, and W. G. Ferlin, "Expression of CD94-NKG2A inhibitory receptor is restricted to a subset of $\mathrm{CD}^{+} \mathrm{T}$ cells," Trends in Immunology, vol. 24, no. 4, pp. 162-164, 2003.

[22] J. M. Moser, J. Gibbs, P. E. Jensen, and A. E. Lukacher, "CD94NKG2A receptors regulate antiviral $\mathrm{CD}^{+} \mathrm{T}$ cell responses," Nature Immunology, vol. 3, no. 2, pp. 189-195, 2002.

[23] S. I. Khakoo, C. L. Thio, M. P. Martin et al., "HLA and NK cell inhibitory receptor genes in resolving hepatitis $\mathrm{C}$ virus infection," Science, vol. 305, no. 5685, pp. 872-874, 2004.

[24] M. P. Martin, X. Gao, J.-H. Lee et al., "Epistatic interaction between KIR3DS1 and HLA-B delays the progression to AIDS," Nature Genetics, vol. 31, no. 4, pp. 429-434, 2002.

[25] M. P. Martin, Y. Qi, X. Gao et al., "Innate partnership of HLA-B and KIR3DL1 subtypes against HIV-1," Nature Genetics, vol. 39, no. 6, pp. 733-740, 2007.

[26] M. Carrington, S. Wang, M. P. Martin et al., "Hierarchy of resistance to cervical neoplasia mediated by combinations of killer immunoglobulin-like receptor and human leukocyte antigen loci," Journal of Experimental Medicine, vol. 201, no. 7, pp. 1069-1075, 2005.

[27] M. López-Botet, A. Angulo, and M. Gumá, "Natural killer cell receptors for major histocompatibility complex class I and related molecules in cytomegalovirus infection," Tissue Antigens, vol. 63, no. 3, pp. 195-203, 2004.

[28] X. Gao, Y. Jiao, L. Wang et al., "Inhibitory KIR and specific HLA-C gene combinations confer susceptibility to or protection against chronic hepatitis B,' Clinical Immunology, vol. 137, no. 1, pp. 139-146, 2010.

[29] N. Pan, W. Jiang, H. Sun et al., "KIR and HLA loci are associated with hepatocellular carcinoma development in patients with hepatitis B virus infection: a case-control study," PLOS ONE, vol. 6, no. 10, Article ID e25682, 2011.

[30] L. L. Lanier, "NK cell recognition," Annual Review of Immunology, vol. 23, pp. 225-274, 2005.

[31] M. A. Karan, N. E. Tascioglu, A. O. Ozturk, S. Palanduz, and M. Carin, "The role of HLA antigens in chronic hepatitis B virus infection," Journal of the Pakistan Medical Association, vol. 52, no. 6, pp. 253-256, 2002.

[32] A. Albayrak, M. Ertek, M. A. Tasyaran, and I. Pirim, "Role of HLA allele polymorphism in chronic hepatitis B virus infection and HBV vaccine sensitivity in patients from eastern Turkey," Biochemical Genetics, vol. 49, no. 3-4, pp. 258-269, 2011.

[33] A. Ramezani, M. R. Hasanjani Roshan, E. Kalantar et al., "Association of human leukocyte antigen polymorphism with outcomes of hepatitis B virus infection," Journal of Gastroenterology and Hepatology, vol. 23, no. 11, pp. 1716-1721, 2008.

[34] S.-H. Hwang, Y.-H. Sohn, H.-B. Oh et al., "Human-leukocyte antigen alleles and haplotypes associated with chronicity of hepatitis B virus infection in Koreans," Archives of Pathology and Laboratory Medicine, vol. 131, no. 1, pp. 117-121, 2007. 


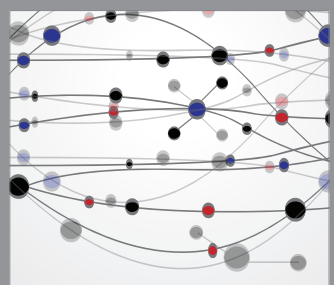

The Scientific World Journal
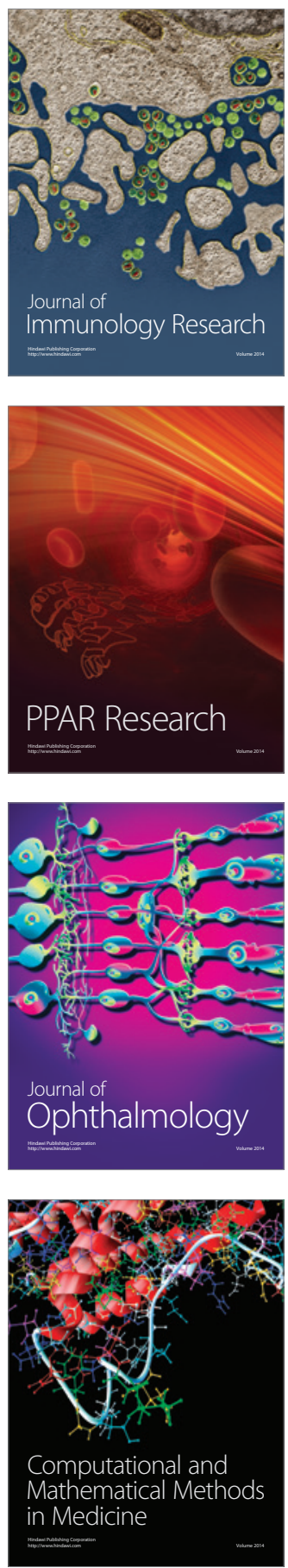

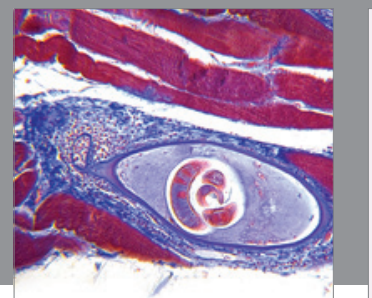

Gastroenterology

Research and Practice
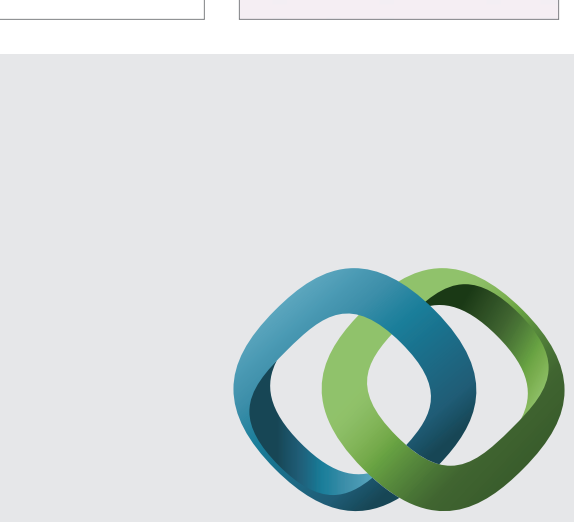

\section{Hindawi}

Submit your manuscripts at

http://www.hindawi.com
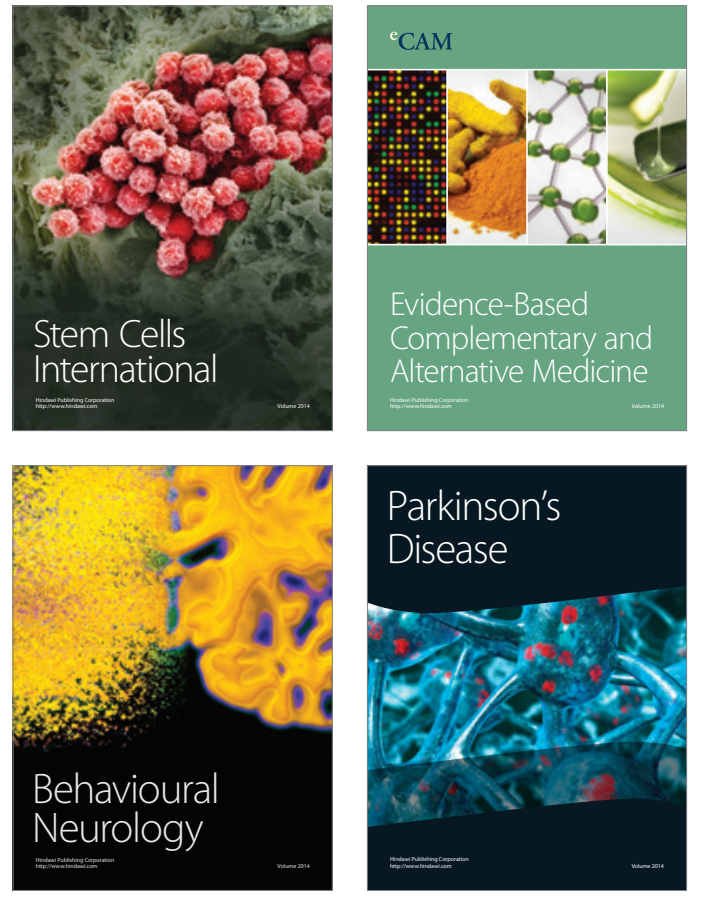
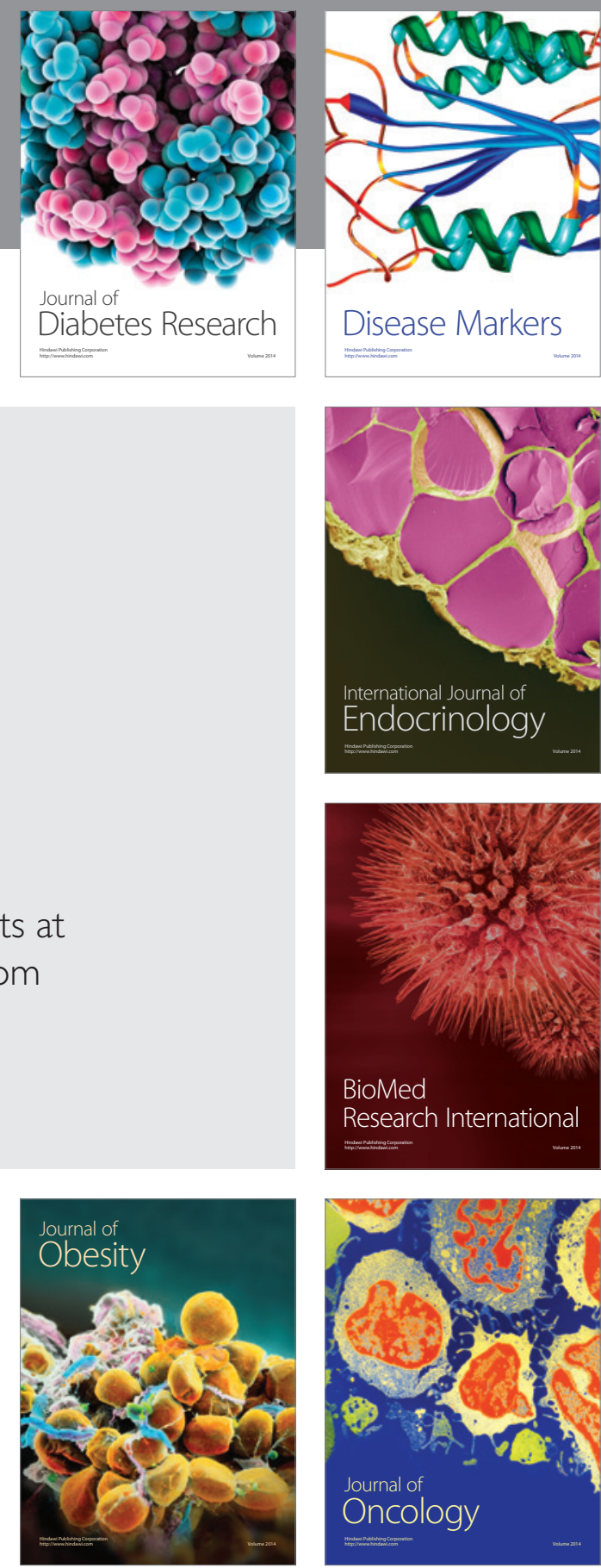

Disease Markers
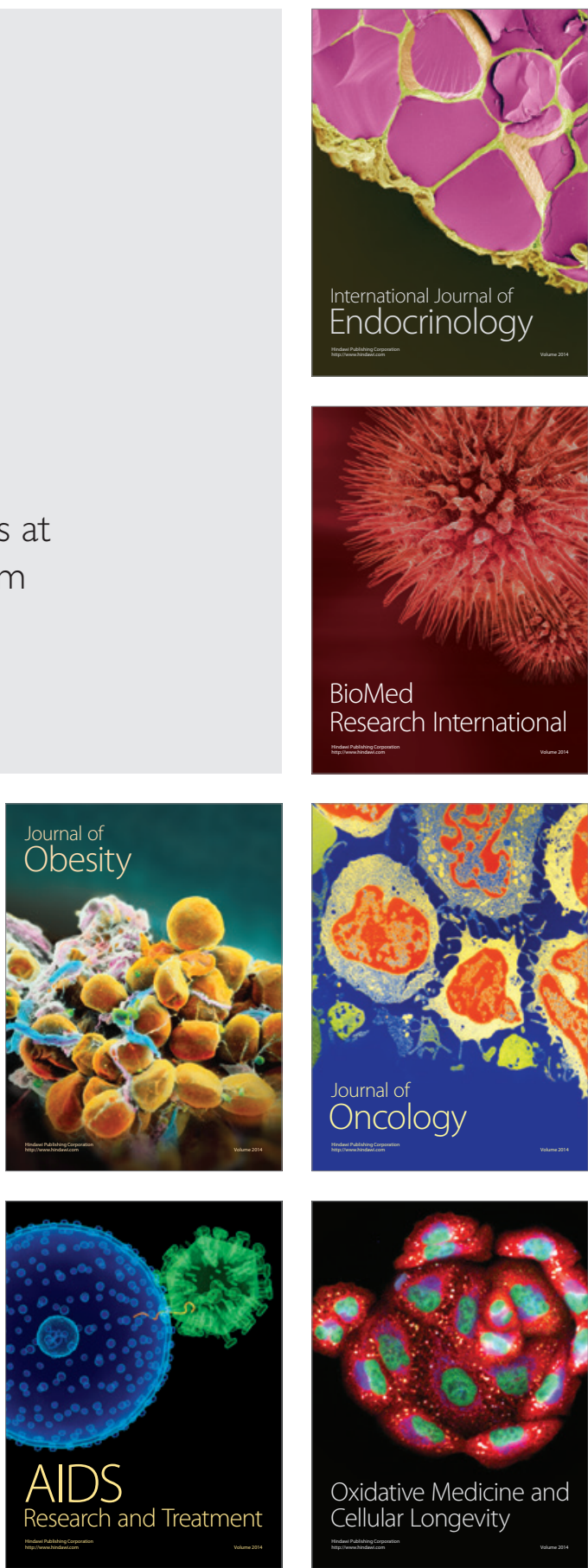